\title{
Correlates of a University Counseling Center's Perceived Service Promptness
}

\author{
Gary Blau ${ }^{1}$, Peter A DeMaria, $\mathrm{Jr}^{2} \&$ John DiMino ${ }^{2}$ \\ ${ }^{1}$ Human Resource Management Department, Fox School of Business, Temple University, Philadelphia, USA \\ ${ }^{2}$ Tuttleman Counseling Services, Temple University, Philadelphia, USA \\ Correspondence: Gary Blau, Human Resource Management Department, Temple University, 349 Alter Hall, \\ 1810 Liacouras Walk, Philadelphia, PA, 19122, USA. E-mail: gblau@temple.edu
}

Received: April 15, 2017

doi:10.5539/jedp.v7n2p24
Accepted: May 8, 2017

Online Published: May 22, 2017

URL: http://doi.org/10.5539/jedp.v7n2p24

\begin{abstract}
The overall goal of this study was to explore the usefulness of a Perceived Service Promptness (PSP) measure for University Counseling Centers (UCCs). As UCCs compete for university resources, helping a client as quickly as possible or PSP can help to support a UCC's documented ability to meet increasing client demands. Since no prior empirical research was found measuring PSP at a UCC, a four-item measure, adapted from a more general quality of service scale, was used. From August 2014 to May 2016, one hundred and seventeen non-urgent undergraduate students seeking counseling services filled out an online survey measuring demographics, client perceptions, wait measures, PSP and recommending the university. Confirmatory factor analysis and scale reliability data psychometrically supported the PSP scale. Correlational analyses showed that both wait time and wait bother experience were each significantly negatively related to PSP. However, hierarchical regression analyses showed that wait bother experience, but not wait time, significantly explained PSP beyond prior controlled-for demographic and client perception variables. In addition, PSP positively explained recommending the university beyond demographic, client perception and wait measures. Research limitations and future research issues are discussed.
\end{abstract}

Keywords: university counseling center, perceived service promptness, wait experience, recommend university

\section{Introduction}

There has been a dramatic increase in college student demand for University Counseling Center (UCC) services (Gallagher, 2014). Brunner, Wallace, Reymann, Sellers and McCabe (2014, p. 264) noted that this may be the "most stressed" generation of college students. A study of stress tolerance in a sample of millennial college students (Bland, Melton, Welle, \& Bigham, 2012) showed that of the 29 lifestyle habits and coping skills assessed, only one, i.e., felt supported by family, friends and teachers, was a significant factor for helping high stress tolerance. A qualitative study showed that university professionals perceived that millennial college students depended on others for problem solving (Much, Wagener, Breitkreuetz, \& Hellenbrand, 2014). A UCC can represent an important base of at least temporary support for millennial college students (Brunner et al., 2014).

Many UCCs have adopted a triage system to help meet this increased demand (Rockland-Miller \& Eells, 2006; Shaffer et al., 2017). In a triage system, clients receive an initial screening evaluation and those classified as urgent (e.g., a danger to self or others, severe or psychotic symptoms) are given priority appointments and seen quickly. Non-urgent clients may have to wait to begin counseling. Research has found that a longer wait time for non-urgent clients led to higher subsequent no-show rate for beginning counseling (DiMino \& Blau, 2012). What variables affect the relationship between wait time and showing up to begin counseling for non-urgent clients is in need of further study. One variable may be Perceived Service Promptness (PSP) of the UCC. In other words, does a non-urgent client perceive that the UCC wants to help him/her as quickly as possible? The overall goal of this study was to explore the usefulness of a PSP measure for UCCs.

While trying to meet increased service demand, UCCs need to compete with other campus service stakeholders for resources (Brunner et al., 2014; Hunt, Watkins, \& Eisenberg, 2012). In the current context of increased 
accountability and restricted budgets, research can help to document a UCC's ability to meet increased service demand. Valotta (2012) noted that client assessment measures are needed to help with planning UCC staffing and budgeting. Measuring PSP of a UCC can assist with such planning efforts. The positive responsiveness of a UCC, as 24/7 available service for students, can also have positive implications for a university's public relations and student recruitment (Bishop, 2010). The purposes of this study are to: (1) test the adaptability of a general service responsiveness scale for measuring UCC PSP; (2) investigate client perception and wait measure correlates of PSP; and (3) test if PSP can significantly explain recommending a university beyond controlled-for demographic, client perception and wait measure variables. Given the lack of prior research, these three issues are framed as separate research questions.

\subsection{Measuring UCC PSP}

PSP falls within the larger construct of service quality (Parasuraman, Zeithaml, \& Berry, 1988). Quality of service across organizations has been successfully measured at the general consumer level using SERVQUAL, a 22-item measure broken down into five dimensions: tangibles, reliability, responsiveness, assurance, and empathy (Parasuraman et al., 1988). Responsiveness in SERVQUAL is measured by four items focusing on perceived promptness (helping as quickly as possible) in receiving service. Given the absence of an existing PSP measure applied to UCCs, these four items were adapted from SERVQUAL to measure PSP in this study.

Focusing on student samples in general health care settings, there has been limited research on PSP. One study measuring student perceptions of service quality at a student health center (Canel \& Anderson Fletcher, 2001) found there was a large gap between higher student expectations versus the perceptions of health center employees' "willingness to help". A second student healthcare setting study found that perceived promptness was positively related to student satisfaction (Senic \& Marinkovic, 2013). A recent qualitative study (Randall \& Bewick, 2016) looked at counselor perceptions in the United Kingdom for improving service quality to students. Work style changes, including improved recording/note keeping processes, resulted in a more efficient service that was perceived to be more acceptable to students (Randall \& Bewick, 2016). However, no prior empirical research was found specifically measuring UCC PSP. This leads to the first research question:

RQ1-Can an existing general service responsiveness scale can be adapted to adequately measure UCC PSP?

\subsection{Antecedents of UCC PSP}

Level of mental distress can motivate a student to seek counseling (Brunner, Wallace, Reymann, Sellers, \& McCabe, 2014). However, perceived stigma for receiving psychological help can prevent a student from seeking counseling (Golberstein, Eisenberg, \& Gollust, 2008). Making students more aware of and comfortable with seeking campus mental health services, such as reducing the stigma of receiving psychological help, should be part of a university's academic mission (Mowbray et al., 2006). For hesitant students, a longer wait time may serve as a roadblock to seeking services.

In a study with a very different patient population, longer perceived waiting time led to lower patient satisfaction for radiological outpatients across 6 hospitals in Belgium (Bielen \& Demoulin, 2007). In a study with non-urgent undergraduate clients at a UCC, clients who reported waiting less than 2 weeks for their intake appointment perceived a lower stigma for receiving psychological help, stronger institutional commitment and a higher willingness to recommend the university to others, versus clients waiting more than 2 weeks (Blau et al., 2015). UCCs typically measure client wait time as part of their service assessment process (Shaffer et al., 2017). In addition to amount of waiting time, "wait experience" may be important to assess. Dissatisfaction with the wait experience (wait bother) led to lower perceived service quality for customers of a university cafeteria (Lee \& Lambert, 2005). The above-cited research collectively suggests that perceived stigma for counseling, level of mental distress, wait time and wait bother experience may negatively affect PSP. This suggests the second research question:

RQ2-Will perceived stigma for counseling, level of mental distress, wait time and wait bother experience each be negatively related to $P S P$ ?

\subsection{UCC PSP Related to Recommending a University}

A UCC is generally considered to be part of campus support services, which has been found to predict student satisfaction (Elliott \& Healy, 2001). Bielen and Demoulin (2007) found that higher patient satisfaction led to a higher likelihood of recommending the radiological services to relatives. Bishop (2010) noted that UCCs may positively contribute to the general recruitment of prospective students. UCC clients who have higher PSP may be more likely to recommend their university to others. For this relationship, PSP is being used as an 
independent variable. Prior research (e.g., Winterrowd, Priniski, Achter, \& Abhold, 2016) investigating outcomes of UCC counseling has recommended controlling for demographic variables (e.g., gender, ethnic background, age, status entering university). Controlling for demographic and other study variables first will allow for a stronger assessment of PSP impact. This suggests the third research question:

RQ3-Will PSP positively impact recommending a university beyond controlled-for demographic, client perception and wait measure variables?

\section{Methods}

\subsection{Participants and Procedure}

The study was conducted at a large urban public university in the Mid-Atlantic region of the United States. From August 2014 to May 2016, 117 undergraduate students who presented at the UCC (Tuttleman Counseling Services) seeking counseling services and were determined to be non-urgent (i.e., did not report suicidality or risk to self/others), completed the survey questionnaire after triage and before intake. Institutional Review Board (IRB) approval was given for all data collection. Survey responses went directly into a Qualtrics' data base. Consistent with recent national surveys, students indicated that anxiety (42\%) and depression (27\%) were the main reasons for coming to the UCC (Brunner et al., 2014).

\subsection{Measures}

The survey consisted of five measurement sections: (1) respondent demographics; (2) client perceptions; (3) wait measures; (4) perceived service promptness, and (5) recommending the university. Unless otherwise noted below, items used a seven-point Likert response scale, from $1=$ strongly disagree to $7=$ strongly agree. A small pilot test of item content for survey measures was done among four UCC clinicians and 10 undergraduate student interns at the UCC's self-help center. The clinicians' feedback qualitatively supported the content validity of the items (Nunnally, 1978), while the interns found the item language understandable for respondents. Cronbach's alpha for estimating the internal consistency reliability for each multi-item measure is reported.

\subsubsection{Respondent Demographics}

Gender, ethnic background, status entering university, current residential status, referral source for counseling (i.e., self-versus-other), and age were measured. A demographic breakdown of the UCC client sample showed: $69 \%$ female students; $73 \%$ white versus $27 \%$ non-white; $74 \%$ percent were non-transfer students versus $26 \%$ transfer students; $21 \%$ percent were commuter versus $79 \%$ were residential students; and $59 \%$ were self-referred with the remaining $41 \%$ were referred by others (e.g., family, university staff) to the UCC. Mean age was 20 years old. By comparison, for the fall of 2016, based on 28,203 matriculated undergraduates at the university: $53 \%$ were female, $57 \%$ were white, and $65 \%$ were non-transfer, and the mean age was 22 years old. Thus in terms of representativeness, the UCC client sample has higher percentages of female, white, and non-transfer students who are generally younger. However, the UCC client sample demographics are more consistent with 2014 data from the Association for University and College Counseling Directors Annual Survey (Reetz, Krylowicz, \& Mistler, 2014) on the percentages of female (65\%) and white students (67\%) served by UCCs.

\subsubsection{Client Perceptions}

There are two measures: stigma for counseling and level of mental distress. Stigma for counseling was measured using a five-item scale (Komiya, Good, \& Sherrod, 2000). A sample item is: "it is a sign of personal weakness or inadequacy to see a psychologist for emotional or interpersonal issues". Cronbach's alpha was .85. Level of mental distress was measured using one-item: "Please rate your current level of distress for the mental issue that brought you to counseling". An eight-point response scale used where: $1=$ none, $2=$ very little, $3=\mathrm{a}$ little, $4=$ moderate, $5=$ a lot, $6=$ severe, $7=$ very severe and $8=$ unbearable.

\subsubsection{Wait Measures}

There are two measures, wait time and wait bother experience. Wait time was measured by asking "indicate as best you can how many days you waited between your initial screening or 'walk in' session (triage) and starting to see your assigned counselor (your intake session)". Wait bother experience was measured using one item asking "how you felt about waiting to start with your assigned counselor". A four-point response scale was used where: 1 = the waiting did not bother me at all, 2 = the waiting bothered me a little bit; 3 = the waiting bothered me moderately and $4=$ the waiting bothered me a lot. 


\subsubsection{Perceived Service Promptness (PSP).}

These four items were adapted from the four-item responsiveness measure of SERVQUAL (Parasuraman et al., 1988). Parasuraman et al. (1988) found a Cronbach's alpha of .82, with four-items, using a sample of 200 adult service-user respondents. Parasurman et al. (1988, p. 23) gave the following definition for responsiveness: "willingness to help customers and provide prompt service". This definition was operationalized using the following four items: "I received prompt service from the UCC"; "The UCC told me when my counseling would begin"; "The UCC wanted to help me as quickly as possible"; and "The UCC was not too busy to respond promptly to me". As noted earlier, the response scale for each item was $1=$ strongly disagree to $7=$ strongly agree. This data is analyzed to test RQ1.

\subsubsection{Recommend University}

This three-item measure was previously used (Blau et al., 2015). A sample item is: "I would recommend this university to my family and friends". Cronbach's alpha was .92.

\subsection{Data Analysis}

Confirmatory Factor Analysis (CFA) was used to test the first Research Question (RQ1). For RQ2 and RQ3, with a sample size $\mathrm{n}=117$, significance level of .05 , assuming a medium effect size correlation of .30 , the statistical power was .91 (Cohen, 1969). For RQ2 and RQ3, stepwise regression analyses (Stevens, 1996) were used to evaluate the impact of demographic variables (Step 1), then the incremental impact of client perception variables (Step 2), and then wait measures (Step 3) in three separate models on PSP. In these first three (steps) models, PSP was used as a dependent variable. Binary measures for the demographic variables allowed them to be directly entered in the regression models (Stevens, 1996). Assuming an anticipated effect size of .15 with 11 predictors using a probability level of .05 , with the current sample size, the statistical power was .80 . In the final regression model (Model 4), PSP is used as an independent variable, and the impact of PSP for significantly explaining recommend the university after controlling for demographic, client perception and wait measure variables was tested. For the regression analyses it was determined that the assumptions of no multicollinearity, linearity, and homoscedasticity were satisfactorily met (Stevens, 1996). Care was taken to avoid four common errors associated with hierarchical/stepwise regression: neglect of a theoretical basis for using; violation of causal priority; use in an exploratory manner; and misinterpretation of results (Petrocelli, 2003).

\section{Results}

\subsection{Test of RQ1}

Using CFA, the following fit statistics of the four-items to the PSP construct were found: $X^{2}(2, \mathrm{~N}=117)=2.38$, $\mathrm{p}>$.05; Adjusted Goodness of Fit $(\mathrm{AGFI})=.96$; Comparative Fit Index $(\mathrm{CFI})=.99$; Root Mean Square Residual $(\mathrm{RMR})=.03$; and Root Mean Square Error of Approximation $(\mathrm{RMSEA})=.04$. Thresholds for acceptable fit (Bentler, 1990) should be at least .90 (AGFI, CFI) and less than .08 for error measures (RMR, RMSEA). Prior work has used similar CFA statistics to support recent scales, i.e., Social Identities and Attitudes Scale (Smith \& Cokley, 2016), and College and Career Readiness Counseling Support (Lapan, Poynton, Marcotte, Marland, \& Milam, 2017). Cronbach's alpha for the four-item PSP scale was .79. Each item contributed to the scale reliability, and the average inter-item correlation was $r=.46$. Collectively these results found a psychometrically sound four-item scale for measuring PSP, supporting RQ1.

\subsection{Tests of $R Q 2$ and $R Q 3$}

To make interpretation easier, the aggregate score for a multi-item measure was divided by the number of items so that the mean (M) was based on the measure's response scale. The means, standard deviations and correlations between continuous variables are reported in Table 1. The mean level for PSP was 5.89 out of 7, which indicates a generally high level. Level of mental distress $(\underline{r}=-.20)$, wait time $(\underline{r}=-.35)$ and wait bother experience $(\underline{r}=-.48)$ were each significantly negatively related to PSP. However, perceived stigma for counseling was not related to PSP $(\underline{r}=-.05)$. This indicates partial support for RQ2. Based on translating $\mathrm{r}^{2}$ partial eta squared into Cohen's effect size (Cohen, 1969), level of mental distress is a medium effect size while wait time and wait bother experience are large effect sizes. Finally, PSP was positively related to recommending the university $(\underline{r}=.23)$, which is a medium effect size. 
Table 1. Means, standard deviations, reliabilities and correlations for continuous variables

\begin{tabular}{|c|c|c|c|c|c|c|c|c|c|}
\hline Measure & M & $\mathrm{SD}$ & 1 & 2 & 3 & 4 & 5 & 6 & 7 \\
\hline 1. $\operatorname{Age}^{a}$ & 4.09 & 2.37 & $(\mathrm{NA})^{\mathrm{f}}$ & & & & & & \\
\hline 2. Stigma for Counseling ${ }^{b}$ & 3.39 & 1.39 & -.13 & $(.85)$ & & & & & \\
\hline 3. Level of Mental Distress ${ }^{c}$ & 5.00 & 1.08 & .08 & .13 & (NA) & & & & \\
\hline 4. Wait Time ${ }^{d}$ & 14.84 & 7.67 & .12 & -.12 & .01 & (NA) & & & \\
\hline 5. Wait Bother Experience ${ }^{e}$ & 2.05 & .91 & .17 & .18 & $.20^{*}$ & $.40^{* *}$ & (NA) & & \\
\hline 6. Perceived Service Promptness ${ }^{b}$ & 5.89 & 1.03 & .01 & -.05 & $-.20^{*}$ & $-.35 * *$ & $-.48 * *$ & $(.79)$ & \\
\hline 7. Recommend University ${ }^{\mathrm{b}}$ & 5.79 & 1.25 & -.09 & -.11 & $-.25 * *$ & -.01 & -.15 & $.23 *$ & $(.92)$ \\
\hline
\end{tabular}

$\mathrm{N}=117, * \mathrm{p}<.05 ; * * \mathrm{p}<.01$ (two-tailed).

${ }^{\text {a }}$ Age, $1=$ less than 18 years old to $14=$ at least 30 years old, so $2=18$ years old, $3=19$ years old, $4=20$ years old, $5=21$ years old, $6=22$ years old......14 = at least 30 years old.

${ }^{\mathrm{b}}$ Stigma for Counseling, Perceived Service Promptness, and Recommend University, $1=$ strongly disagree to 7 = strongly agree.

${ }^{\mathrm{c}}$ Level of Mental Distress, $1=$ none to $8=$ unbearable.

${ }^{\mathrm{d}}$ Wait Time, $1=1$ day to $41=$ over 40 days.

${ }^{\mathrm{e}}$ Wait Bother Experience, 1 = waiting did not bother me at all to 4 = waiting bothered me a lot.

${ }^{\mathrm{f}}$ (Coefficient alpha), NA = not applicable.

Table 2 shows the stepwise regression model results for testing the RQ2 and RQ3. For RQ2, Models 1, 2 and 3 evaluate the impact of variables for explaining PSP as the dependent variable. Looking at the impact of variables for explaining PSP first, the initial significance of several demographic variables in Models 1 and 2, i.e., being a transfer student, commuter and self-referral, and level of mental distress (Model 2 only) impacting PSP decrease to non-significance in Model 3. In Model 3 only wait bother experience $(b=-.427)$ significantly negatively affects PSP, but wait time does not $(b=-.110)$. The results of Model 3 provide very limited support for RQ2. Model 4 evaluates the impact of adding in PSP, as an independent variable, to explain recommending the university as the dependent variable, beyond the demographic, client perceptions and wait measure variables. Model 4 finds that being a non-commuter $(b=-.252)$, and PSP $(b=.264)$, each significantly increase recommending the university. PSP significantly explains additional significant variance $\left(\mathrm{R}^{2}=4.4 \%\right)$ in recommending the university beyond controlled for variables. This result supports RQ3. Overall, $35 \%$ of the variance $\left(\mathrm{R}^{2}\right)$ was explained for PSP and $17 \%$ for recommending the university.

Table 2. Results of stepwise regression analyses on perceived service promptness and recommend university

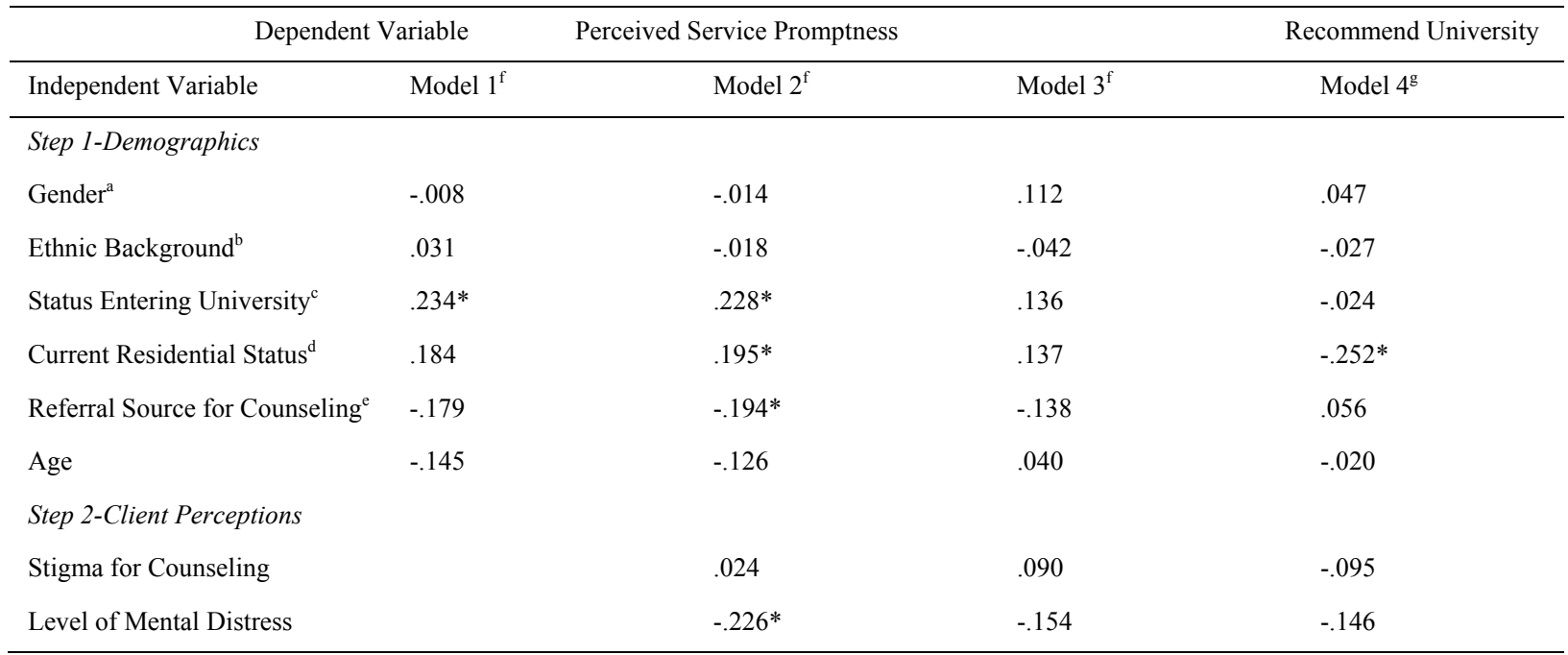




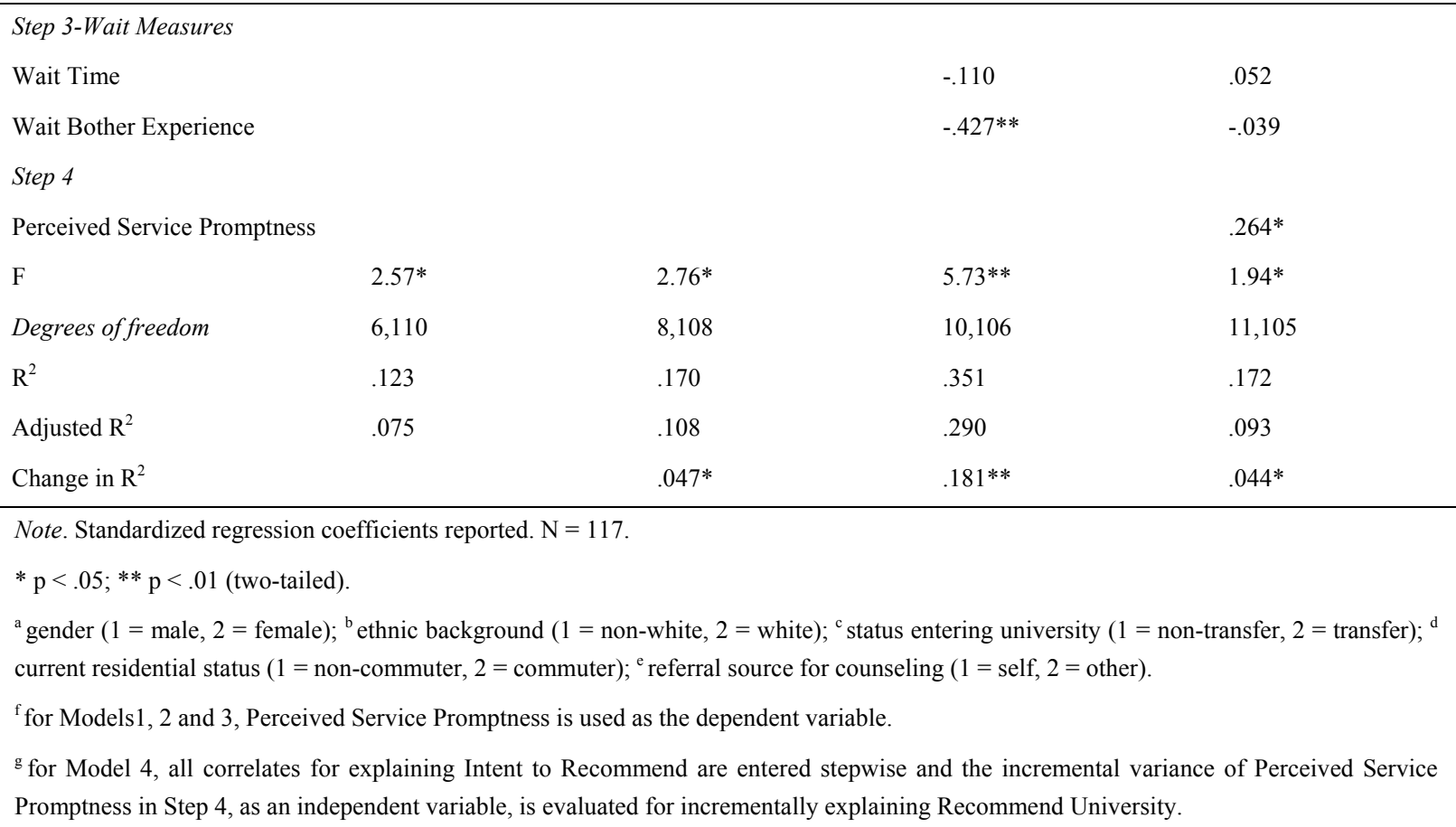

\section{Discussion}

Kitzrow (2009, p. 657) noted the importance of college student mental health issues "as an institutional responsibility and priority". With the demand for UCC services increasing (Gallagher, 2014) investigating PSP is an important client assessment measure. To the authors' knowledge this is the first application of a stand-alone PSP measure to a UCC. This study demonstrated that PSP can be measured using a four-item scale, adapted from the four-item responsiveness measure of SERVQUAL (Parasuraman et al., 1988). The present study also showed that significant initial correlates of lower PSP were: clients' higher levels of mental distress when coming to counseling, waiting longer for intake, and waiting to start counseling really bothering them (wait bother). Although perhaps intuitive, these findings reinforce that it is important that UCCs systematically gather mental distress and wait-related data as part of their client assessment process (Kitzow, 2009; Valotta, 2012).

Addressing the needs of non-urgent "higher distress-wait bothered" clients may be important in order to facilitate clients presenting to their intake appointment to begin counseling. Of course, this can be challenging during UCC peak demand periods for counseling services. Alternative strategies to "hold" these clients after triage and until intake (Kitzrow, 2009) may be necessary (e.g., psychoeducational groups, drop-in counseling, self-help centers). Prior research has shown that a longer wait time after triage led to a higher no show rate at intake (DiMino \& Blau, 2012). However, DiMino and Blau (2012) did not measure wait experience. This study showed that the perceived wait bother experience is more important than wait time in affecting PSP. Research is needed to investigate if wait experience is a stronger antecedent of subsequent show rate than wait time. In addition, higher PSP had a significant positive impact on the recommending the university beyond demographics, client perceptions and wait measures. This reinforces that a UCC can help with prospective student recruitment (Bishop, 2010), and be a positive source for public relations for a university (Blau et al., 2015; Brunner et al., 2014).

\section{Study Limitations}

A number of limitations exist. Unfortunately, data for show/no-show rate at subsequent intake could not be collected. All data are self-reported and cross-sectional, including the retrospective estimate of days waited to begin counseling after triage. It should be noted that the self-reported mean wait time of 15 days for this UCC sample was very consistent with the record-based 16-day mean wait time, using a separate prior sample at the same UCC, reported by DiMino and Blau (2012). One-item measures for mental distress level and wait bother experience do not allow for calculating reliability estimates. However, a one-factor test (Podsakoff, Mackenzie, Lee, \& Podsakoff, 2003), showed that eight factors had eigenvalues over 1 and the first factor accounted for $18 \%$ 
of the total variance. This suggests that method variance is not an overriding limitation for the study findings. The sample was restricted to undergraduates at a large urban, public university UCC site. Future research testing the generalizability of results, including the PSP measure, using other undergraduate samples at other UCC sites (e.g., smaller, private universities) is needed.

\section{Implications for Practice and Future Research}

Millennial college students often lack patience (Bland et al., 2012; Rickes, 2009). As student demand for UCC services continues to increase (Gallagher, 2014; Reetz et al., 2014), evaluating PSP and the variables affecting PSP, such as client mental distress level, wait time, and wait experience, are important to study. Moore and Owen (2014) have advocated for UCCs exploring procedures that could improve their service delivery. A UCC can establish a baseline measure of PSP and then use subsequent measures to evaluate if PSP is improving, holding steady or decreasing. Such measurement can be part of a general quality improvement assessment process (Maffini \& Toth, 2017). Decreasing PSP, along with other data, may suggest that a re-assessment of UCC staffing, including additional hiring, is required (Valotta, 2012). Following the recommendation of the International Association of Counseling Services or IACS (2010, p. 20), "every effort should be made to maintain minimum staffing ratios in the range of one FTE professional staff member (excluding trainees) for every 1,000-1500 students, depending on services offered and other campus mental health agencies".

Higher PSP of a UCC can also have positive implications for the university's public relations and student recruitment (Bishop, 2010). Non-urgent undergraduate clients who waited less than 2 weeks for intake had stronger institutional commitment and a higher willingness to recommend the university to others, versus clients waiting more than 2 weeks (Blau et al., 2015). With the general availability of social media (e.g., Facebook), college students have access to increasing numbers of friends and acquaintances (Ellison, Steinfield, \& Lampe, 2007). Such social media can help transfer students integrate more successfully socially into a receiving university (Nehls \& Smith, 2014). Students who perceive higher PSP of a UCC may serve as "good-will ambassadors" for a university, i.e., be more likely to recommend the university to others. Research has shown that knowing someone who attended a university positively affected prospective students' perceptions of the school's atmosphere, e.g., "it feels right", "it's where I belong" (Pampaloni, 2010, p. 41). Consistently demonstrating a relationship between PSP and recruitment outcomes over time may help a UCC to leverage this relationship for more university resources.

\section{Conclusion}

The overall goal of this study was to explore the usefulness of a PSP measure for UCCs. The results of this study suggest a promising four-item scale for measuring PSP. In future research, wait experience data needs to be collected and evaluated against wait time for its impact on subsequent client show rate. The use of measures, such as PSP, in proactive research strategies can help to: demonstrate the positive impact of UCC on a University; justify a UCC's demand for resources; and provide fact-based recommendations for UCCs to help improve their services (Castonguay, Locke, \& Hayes, 2011; Maffini \& Toth, 2017).

\section{References}

Bentler, P. (1990). Comparative fit indexes in structural models. Psychological Bulletin, 107, 238-246. https://doi.org/10.1037/0033-2909.107.2.238

Bielen, F., \& Demoulin N. (2007). Waiting time influence on the satisfaction-loyalty relationship in services. Managing Service Quality: An International Journal, 17, 174-193. https://doi.org/10.1108/09604520710735182

Bishop, J. (2010). The counseling center: An undervalued resource in recruitment, retention and risk management. Journal of College Student Psychotherapy, 24, 248-260. https://doi.org/10.1080/87568225.2010.509219

Bland, H. W., Melton, B. F., Welle, P., \& Bigham, L. (2012). Stress tolerance: New challenges for millennial college students. College Student Journal, 46(3), 362-375.

Blau, G., DiMino, J., Sheridan, N., Stein, A., Casper, S., Chessler, M., \& Beverly, C. (2015). Wait time for counseling affecting perceived stigma and attitude toward the university. College Student Journal, 49(2), 280-290. 
Brunner, J. L., Wallace, D. L., Reymann, L. S, Sellers, J.-J., \& McCabe, A. G. (2014). College counseling today: Contemporary students and how counseling centers meeting their needs. Journal of College Student Psychotherapy, 28, 257-324. https://doi.org/10.1080/87568225.2014.948770

Canel, C., \& Anderson Fletcher, E. (2001). An analysis of service quality at a student health center. International Journal of Health Care Quality Assurance, 14(6), 260-267. https://doi.org/10.1108/09526860110404220

Castonguay, L., Locke, B., \& Hayes, J. (2011). The Center for Collegiate Mental Health: An example of a practice-research network in university counseling centers. Journal of College Student Psychotherapy, 25(2), 105-119. https://doi.org/10.1080/87568225.2011.556929

Cohen, J. (1969). Statistical power analysis for the behavioral sciences. New York, NY: Academic.

DiMino, J., \& Blau, G. (2012). The relationship between wait time after triage and show rate for intake in a non-urgent student population. Journal of College Student Psychotherapy, 26, 241-247. https://doi.org/10.1080/87568225.2012.685857

Elliott, K. M., \& Healy, M. A. (2001). Key factors influencing student satisfaction related to recruitment and retention. Journal of Marketing for Higher Education, 10(4), 1-11. https://doi.org/10.1300/J050v10n04_01

Ellison, N., Steinfield, C., \& Lampe, C. (2007). The benefits of Facebook "friends": Social capital and college students' use of online social network sites. Journal of Computer-Mediated Communication, 12, 1143-1168. https://doi.org/10.1111/j.1083-6101.2007.00367.x

Gallagher, R. P. (2014). National Survey of College Counseling 2014 (Monograph Series Number 9V). Published by The International Association of Counseling Services, Inc. Retrieved from http://www.collegecounseling.org/wp-content/uploads/NCCCS2014_v2.pdf

Golberstein, E., Eisenberg, D., \& Gollust, S. E. (2008). Perceived stigma and mental health care seeking. Psychiatric Services, 59(4), 392-399. https://doi.org/10.1176/ps.2008.59.4.392

Hunt, J. B., Watkins, D., \& Eisenberg, D. (2012). How do college campuses make decisions about allocating resources for student mental health?: Findings from key participant interviews. Journal of College Student Development, 53(6), 850-856. https://doi.org/10.1353/csd.2012.0083

IACS. (2010). Accreditation for the University and College Counseling Services. Alexandria, VA: International Association of Counseling Services, Inc.

Kitzrow, M. A. (2009). The mental health needs of today's college students: Challenges and recommendations. NASPA Journal, 46(4), 646-660. https://doi.org/10.2202/1949-6605.5037

Komiya, N., Good, G., \& Sherrod, N. (2000). Emotional openness as a predictor of college students' attitudes toward seeking psychological help. Journal of Counseling Psychology, 47(1), 138-143. https://doi.org/10.1037/0022-0167.47.1.138

Lapan, R., Poynton, T., Marcotte, A., Marland, J., \& Milam, C. (2017). College and Career Readiness Support scales. Journal of Counseling \& Development, 95(1), 77-86. https://doi.org/10.1002/jcad.12119

Lee, W., \& Lambert, C. U. (2005). The effect of waiting time and affective reactions on customers' evaluation of service quality in a cafeteria. Journal of Foodservice Business Research, 8, 19-37. https://doi.org/10.1300/J369v08n02_03

Maffini, C. S., \& Toth, P. L. (2017). Quality improvement in university counseling centers. Journal of College Student Psychotherapy, 31(1), 43-58. https://doi.org/10.1080/87568225.2016.1254000

Moore, J., \& Owen, J. (2014). Assessing outcomes: Practical methods and evidence. Journal of College Counseling, 17, 175-185. https://doi.org/10.1002/j.2161-1882.2014.00056.x

Mowbray, C., Megivern, D., Mandiberg, J., Strauss, S., Stein, C., Collins, K., ... Lett, R. (2006). Campus mental health services: Recommendations for change. American Journal of Orthopsychiatry, 76, 226-237. https://doi.org/10.1037/0002-9432.76.2.226

Much, K., Wagener, A. M., Breitkreutz, H. L., \& Hellenbrand, M. (2014). Working with the Millennial Generation: Challenges facing $21^{\text {st }}$-Century students from the perspective of university staff. Journal of College Counseling, 17(2), 37-47. https://doi.org/10.1002/j.2161-1882.2014.00046.x

Nehls, K., \& Smith, B. D. (2014). The role of Facebook in fostering transfer student integration. Journal of Student Affairs Research and Practice, 51(4), 392-406. https://doi.org/10.1515/jsarp-2014-0040 
Nunnally, J. (1978). Psychometric theory (2nd ed.). New York, NY: McGraw Hill.

Pampaloni, A. (2010). The influence of organizational image on college selection: What students seek in institutions of higher education. Journal of Marketing for Higher Education, 20(1), 19-48. https://doi.org/10.1080/08841241003788037

Parasuraman, A., Zeithaml, V., \& Berry, L. (1988). Multiple-item scale for measuring consumer perceptions of service quality. Journal of Retailing, 64(1), 12-40.

Petrocelli, J. V. (2003). Hierarchical multiple regression in counseling: Common problems and possible remedies. Measurement and Evaluation in Counseling and Development, 36, 9-22.

Podsakoff, P., Mackenzie, S., Lee, J., \& Podsakoff, N. (2003). Common method biases in behavioral research: A critical review of the literature and recommended remedies. Journal of Applied Psychology, 88(5), 879-903. https://doi.org/10.1037/0021-9010.88.5.879

Randall, E., \& Bewick, B. (2016). Exploration of counsellors' perceptions of the redesigned service pathways: A qualitative study of a UK university counselling service. British Journal of Guidance \& Counseling, 44, 86-98. https://doi.org/10.1080/03069885.2015.1017801

Reetz, D. R., Krylowicz, B., \& Mistler, B. (2014). The Association for University and College Counseling Directors Annual Survey. Retrieved from http://www.aucced.org/assets/documents/2014\%20aucccd\%20monograph\%20-\%20public\%20pdf.pdf

Rickes, P. (2009). Make way for Millenials!: How today's college students are shaping higher education space. Planning for Higher Education, 37(2), 7-17.

Rockland-Miller, H., \& Eells, G. (2006). The implementation of mental health clinical triage in university health services. Journal of College Student Psychotherapy, 20(1), 39-51. https://doi.org/10.1300/J035v20n04_05

Senic, V., \& Marinkovic, V. (2013). Patient care, satisfaction and service quality in health care. International Journal of Consumer Studies, 37, 312-319. https://doi.org/10.1111/j.1470-6431.2012.01132.x

Shaffer, K. S., Love, M. M., Chapman, K. M., Horn, A. J., Haak, P. P., \& Shen, C. Y. W. (2017). Walk-in triage systems in university counseling centers. Journal of College Student Psychotherapy, 31(1), 71-89. https://doi.org/10.1080/87568225.2016.1254005

Smith, L. V., \& Cokley, K. (2016). Stereotype threat vulnerability: A psychometric investigation of the Social Identities and Attitudes Scale. Measurement and Evaluation in Counseling and Development, 49(2), 145-162. https://doi.org/10.1177/0748175615625752

Stevens, J. (1996). Applied Multivariate Statistics for the Social Sciences (3rd ed.). Mahwah, NJ: Erlbaum.

Valotta, L. (2012). Toward a more data-driven supervision of collegiate college centers. Journal of American College Health, 60, 336-339. https://doi.org/10.1080/07448481.2012.663843

Winterrowd, E., Priniski, S. J., Achter, D., \& Abhold, J. J. (2016). Correlates of satisfaction, intrapersonal learning, and academic outcomes at counseling centers in a university system. College Student Journal, 50(2), 288-301.

\section{Copyrights}

Copyright for this article is retained by the author(s), with first publication rights granted to the journal.

This is an open-access article distributed under the terms and conditions of the Creative Commons Attribution license (http://creativecommons.org/licenses/by/4.0/). 